\title{
Application of ultrasound for degradation of benzophenone-3 in aqueous solutions
}

\author{
H. Zúñiga-Benítez ${ }^{1}$ J. Soltan ${ }^{2}$ G. A. Peñuela ${ }^{1}$
}

Received: 18 February 2014/Revised: 1 May 2015 / Accepted: 4 July 2015/Published online: 4 August 2015

(C) Islamic Azad University (IAU) 2015

\begin{abstract}
This paper reports the results of an experimental work on sonochemical degradation of benzophenone-3 (BP3), one of the most commonly used ultraviolet (UV) filters whose disruptive effect on the endocrine system of various living beings has been demonstrated. Ultrasound irradiation is a promising advanced oxidation technology that has received considerable interest as an alternative for degradation of persistent organic pollutants through hydroxyl free radicals that are generated from the cavitation bubbles implosion. Taking into account the potential risk due to the presence of BP3 in the environment and its possible removal using ultrasound, the effect of operating parameters such us ultrasonic applied power, pollutant initial concentration, $\mathrm{pH}$, the presence of gases (including ozone), inorganic anions and alcohols on the substrate removal was investigated. During sonochemical treatment, a higher pollutant degradation rate was achieved by increasing the power in a range of 40.2-80.1 W. Likewise, at lower benzophenone- 3 initial concentrations, higher extents of degradation were observed, which could be explained by a heterogeneous kinetics model. Acidic $\mathrm{pH}$ enhanced the pollutant initial degradation by $21 \%$. Oxygen, ozone and bicarbonate ions affected positively the benzophenone-3 removal, while nitrogen, nitrate and chloride anions inhibited it. Measurements of concentration
\end{abstract}

J. Soltan

j.soltan@usask.ca

1 Grupo GDCON, Facultad de Ingeniería, Sede de Investigación Universitaria (SIU), Universidad de Antioquia, Calle 70 No 52-21, Medellín, Colombia

2 Department of Chemical and Biological Engineering, University of Saskatchewan, 57 Campus Drive, Saskatoon, SK S7N 5A9, Canada of hydroxyl free radicals indicated that by promoting $\mathrm{OH}$. radical formation, the pollutant elimination rate can be increased.

Keywords Advanced oxidation process . Benzophenone-3 · Hydroxyl radicals · Sonochemical degradation $\cdot$ Water treatment

\section{Introduction}

UV-absorbing chemicals (UV filters) are a diverse group of chemical additives included in a wide variety of everyday products (Gago-Ferrero et al. 2012). Benzophenone-3 (2hydroxy-4-methoxybenzophenone, BP3) is one of the most commonly used UV filters. It is employed as sunlight filter in cosmetics, sunbathing lotions, beauty creams, shampoos and other cosmetic formulations, to protect either the skin or other formulation components from the effects of sunlight exposure. This wide range of application is due to the fact that BP3 can absorb, with limited phototransformation, sunlight in the UVA and UVB regions. Likewise, BP3 is not only used in sunscreens and personal care products but also employed to photostabilize packaging materials (food packaging), to prevent polymers photochemical degradation, in the treatment of photodermatitis, and in domestic and industrial commodities or vehicle maintenance products (Gago-Ferrero et al. 2013; Vione et al. 2013).

Contamination of the aquatic environment with UV filters, including benzophenone-3, may occur through two input pathways: directly via wash-off from skin and clothes, or indirectly via wastewater treatment plants (rubbed off by towels, washed off during showering, or from renal excretion after percutaneous or oral uptake) (Balmer et al. 2005; Fent et al. 2010a; Li et al. 2007). BP-3 
has been detected in different aquatic systems (wastewater, lakes, rivers and coastal areas), and there are indications that it can accumulate in fish (Blüthgen et al. 2012; Fent et al. 2010b).

Additionally, benzophenone- 3 has shown estrogen-like activity demonstrated by in vitro and in vivo assays (GagoFerrero et al. 2013). Dermal and oral administration of BP3 to rats and mice has shown alterations in liver, kidney and reproductive organs (Garcia et al. 2011). Likewise, the exposure to elevated levels of benzophenone-type UV filter compounds may be associated with some estrogen-dependent diseases (Gago-Ferrero et al. 2013), and a recent study showed that low concentration of BP3 leads to alteration of genes involved in steroidogenesis and hormonal pathways in zebrafish (Blüthgen et al. 2012). All these reports demonstrate the disruptive effect of BP3 on the endocrine system of different living organisms and demonstrate the need for finding methods for its removal.

Ozonation, peroxone oxidation, photo and fungal degradation, and oxidation with ferrate (VI) have been some of the techniques employed by different groups to remove BP3 (Gago-Ferrero et al. 2012, 2013; Yang and Ying 2013). However, the effectiveness of ultrasound irradiation (US) on the BP3 removal has not been explored. US is a novel advanced oxidation technology whose application for degrading persistent organic pollutants has received considerable interest (Chiha et al. 2011; Dailianis et al. 2014; Mahvi 2009; Méndez-Arriaga et al. 2008). The propagation of ultrasound through a liquid leads to the acoustic cavitation phenomenon in which bubbles are generated from existing gas nuclei in liquids (Chiha et al. 2011; Siddique et al. 2014). The bubbles form, grow and collapse through compression and rarefaction cycles (Mahvi 2009). During the collapse of bubbles, temperature and pressure can reach extreme values (around $5000 \mathrm{~K}$ and hundreds of atmospheres) in a very short period of time (Chiha et al. 2011; Mahvi 2009; Méndez-Arriaga et al. 2008). Under these conditions, different reactive species can be generated. For example, in aqueous systems, reactive hydroxyl free radicals and hydrogen are formed from the thermal dissociation of water vapor (Eq. 1) and reactions of oxygen gas (Eqs. 25) (Chiha et al. 2011).

$$
\begin{aligned}
& \left.\left.\mathrm{H}_{2} \mathrm{O}+()\right)\right) \rightarrow \mathrm{H}^{\cdot}+\mathrm{OH} \\
& \mathrm{O}_{2} \rightarrow 2 \mathrm{O} \\
& \mathrm{H}+\mathrm{O}_{2} \rightarrow \cdot \mathrm{OOH} \\
& \mathrm{O}+\mathrm{H}_{2} \mathrm{O} \rightarrow 2 \cdot \mathrm{OH} \\
& \mathrm{H}+\mathrm{O}_{2} \rightarrow \cdot \mathrm{OH}+\mathrm{O}
\end{aligned}
$$

According to hot spot theory, sonochemical reactions can occur in three different regions: (1) the interior of the collapsing bubbles, (2) the bubble-liquid interfacial region where the hydroxyl free radical reactions are predominant and (3) the bulk of the solution (Chiha et al. 2010, 2011; Henglein 1987). When the sonolysis is conducted in the presence of organic species, a number of chemical processes can occur, depending on the physical and chemical nature of the solute. A volatile and hydrophobic pollutant most probably will be pyrolized inside the bubble of cavitation, while a nonvolatile and hydrophilic compound will be oxidized by the radicals in the interface or the bulk solution (Chiha et al. 2010; Hoffmann et al. 1996).

Taking into account the potential risk due to the presence of BP3 in the environment and its possible removal using ultrasound, the aim of this study was to evaluate the degradation of benzophenone- 3 by ultrasonic treatment and investigate the effect of operating conditions such as $\mathrm{pH}$, pollutant initial concentration, applied power and the presence of dissolved gases (oxygen, nitrogen and ozone), anions and hydroxyl radical scavengers (alcohols) in the solution. This research project was carried out in AprilSeptember, 2013, in the Department of Chemical and Biological Engineering of the University of Saskatchewan (Saskatoon, Canada).

\section{Materials and methods}

Benzophenone-3 containing more than $98 \%$ pure compound was purchased from Alfa Aesar (Ward Hill-MA, USA) and used as received. All solutions were prepared using Milli-Q water $(18.2 \mathrm{M} \Omega \mathrm{cm})$ (Milli-Q Integral system-Millipore, Darmstadt, Germany). Ultrahigh-purity (UHP)-grade oxygen, nitrogen and air were supplied by Praxair (Mississauga, Ontario, Canada). Ozone was produced from pure oxygen using a laboratory ozone generator (Azco Industries LTD VMUS-4S, Langley, BC, Canada). HPLC-grade methanol and acetonitrile were supplied by Sigma-Aldrich (Oakville, Ontario, Canada). The $\mathrm{pH}$ adjustment was carried out with concentrated solutions of sodium hydroxide and nitric acid (Alfa Aesar, Ward Hill, MA, USA). Sodium bicarbonate, potassium nitrate and chloride (Sigma-Aldrich, Oakville, Ontario, Canada) were used to evaluate the effect of the presence of anions in the solution.

An Ultrasonic VCX-500 (Sonics and Materials, Church Hill Road, Newtown, CT, USA) was used as ultrasound generator. Ultrasonic waves $(20 \mathrm{kHz})$ were emitted from the probe (tip diameter: $13 \mathrm{~mm}$, length: $136 \mathrm{~mm}$, material: titanium alloy) which was completely immersed in the solution (ultrasonic probe and horn system). Experiments were conducted in a cylindrical glass reactor. The 
temperature of the solution was monitored using a thermocouple inside the reaction medium and was maintained at $25 \pm 2{ }^{\circ} \mathrm{C}$ using a cooling water bath. The amplitude of vibrations at the probe tip was controlled at four different levels $(40,50,60$ and $65 \%)$. In each sonication, run $200 \mathrm{~mL}$ of solution was processed. In the ozonation and ozone + ultrasound experiments, samples were quenched using a sodium thiosulfate solution. All the runs were conducted in triplicate. The standard deviations and coefficients of variation of the data were below $5 \%$.

Samples of $1 \mathrm{~mL}$ were withdrawn at different time intervals. Benzophenone- 3 concentration was determined using an Agilent Technologies 1100 (Santa Clara, CA, USA) high-performance liquid chromatography (HPLC) system, with a Nova-Pak C-18 column $(150 \mathrm{~mm} \times 4.6 \mathrm{~mm})$ (Milford, MA, USA) and a diode array detector set at $287 \mathrm{~nm}$. An isocratic flow $\left(1 \mathrm{~mL} \mathrm{~min}^{-1}\right)$ of acetonitrile and Milli-Q water (70:30, $\mathrm{v} / \mathrm{v})$ was the mobile phase. The column temperature and injection volume were $30{ }^{\circ} \mathrm{C}$ and $100 \mu \mathrm{L}$, respectively. Dissolved organic carbon (DOC) content was determined using a Shimadzu TOC-L CPH/CPN instrument (Canby, $\mathrm{OR}$, USA). The $\mathrm{OH}$ radical concentration was measured indirectly using dimethyl sulfoxide (DMSO, SigmaAldrich, St. Louis, MO, USA) as a capture agent to produce formaldehyde. The formaldehyde was treated with 2,4-dinitrophenylhydrazine (DNPH, Sigma-Aldrich, St. Louis, MO, USA) to produce formaldehyde-2,4-dinitrophenylhydrazone, which was quantified using HPLC with an Eclipse Plus C-18 column $(150 \mathrm{~mm} \times 4.6 \mathrm{~mm})$ (Agilent Technologies, Santa Clara, CA, USA) and a mixture of acetonitrile and Milli-Q water (45:55, v/v) as mobile phase.

\section{Results and discussion}

\section{Effect of applied ultrasonic power}

Two of the most important parameters in application of ultrasonic treatment in the removal of organic pollutants are the power and frequency employed (Méndez-Arriaga et al. 2008). Thus, four amplitudes of vibration at the probe tip were selected resulting in nominal ultrasonic powers of 40.2, 55.9, 73.8 and $80.1 \mathrm{~W}$.

Ultrasonic energy dissipated in the reactor was estimated using the calorimetric method and Eq. 6 (Mason et al. 1992),

Power $=\left(\frac{\mathrm{d} T}{\mathrm{~d} t}\right) \times C_{p} \times M$

where $C p$ is the heat capacity of the solvent $\left(\mathrm{J} \mathrm{Kg}^{-1} \mathrm{~K}^{-1}\right)$, $M$ is the mass of solvent used $(\mathrm{Kg})$ and $\mathrm{d} T / \mathrm{d} t$ is the variation of the temperature with time. For each system under study, the initial temperature rise $(T)$ was recorded against time $(t)$ at different time intervals. Control experiments indicated that approximately $60 \%$ of the power is transmitted to the solution and the rest is lost mainly in the form of heat.

The effect of input power on the benzophenone-3 sonolytic treatment is shown in Fig. 1. These results indicate that by increasing the power, the extent of degradation of BP3 increases. After 60 min of sonolytic irradiation, a $91.4 \%$ decrease in the pollutant concentration was achieved with the highest power, which represents an improvement of $47.6 \%$ over the minimal power applied. Likewise, in terms of initial degradation rate, calculated as $\Delta C / \Delta t$, it can be noted (data depicted in Fig. 2) that with increasing power from 40.2 to $80.1 \mathrm{~W}$, the initial degradation rate increased, reaching a maximum value around $0.5 \mu \mathrm{M} \mathrm{min}{ }^{-1}$ for $80.1 \mathrm{~W}$ of applied power.

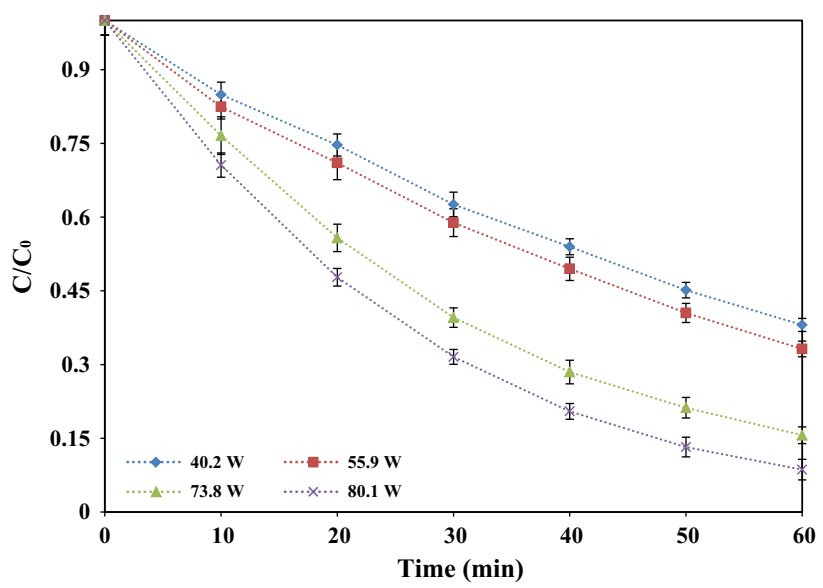

Fig. 1 Effect of the ultrasonic applied power on BP3 degradation [frequency: $20 \mathrm{kHz}$, temperature: $25 \pm 2{ }^{\circ} \mathrm{C}$, pollutant initial concentration: $3.9 \mathrm{mg} / \mathrm{L}, \mathrm{pH}$ : natural (6.5)]

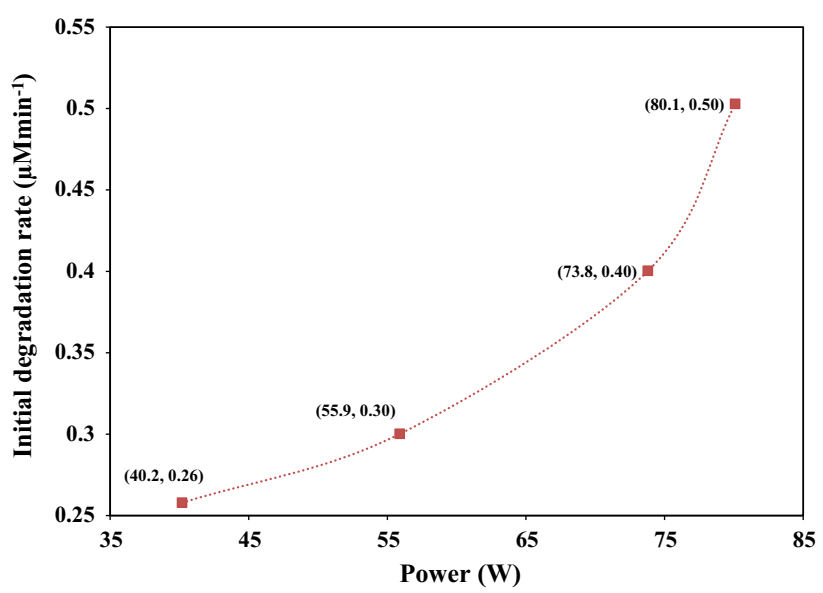

Fig. 2 Effect of the ultrasonic applied power on BP3 initial degradation rate [frequency: $20 \mathrm{kHz}$, temperature: $25 \pm 2^{\circ} \mathrm{C}$, pollutant initial concentration: $3.9 \mathrm{mg} / \mathrm{L}, \mathrm{pH}$ : natural (6.5)] 
Table 1 Physicochemical properties of benzophenone-3 (SRC PhysProp database, 2014)<smiles>COc1ccc(C(=O)c2ccccc2)c(O)c1</smiles>

\begin{tabular}{ll}
\hline Molecular weight $(\mathrm{g} / \mathrm{gmole})$ & 228.25 \\
Water solubility $\left(\mathrm{mg} \mathrm{L}^{-1}\right), 25{ }^{\circ} \mathrm{C}$ & 68.56 \\
Henry's law constant $\left(\mathrm{atm} . \mathrm{m}^{3} \mathrm{~mol}^{-1}\right), 25{ }^{\circ} \mathrm{C}$ & $1.50 \times 10^{-8}$ \\
Octanol/water partition coefficient $\left(\log K_{\mathrm{OW}}\right)$ & 3.79 \\
\hline
\end{tabular}

Table 1 shows the structural formula and some of the physicochemical properties of BP3, respectively. This compound cannot be degraded by pyrolysis inside the cavitation bubble, since its estimated Henry's law constant is $1.5 \times 10^{-8}$ atm. $\mathrm{m}^{3} \mathrm{~mol}^{-1}$ suggesting a low volatility. Additionally, due to its low solubility in water and high octanol/water partition coefficient, BP3 is most probably present at the interface of bubble and solution bulk. Thus, the $\mathrm{OH}$ free radicals generated by ultrasound may be the main species responsible for the substrate degradation.

The number of active cavitation bubbles generated by ultrasound increases with the increase in the irradiation power, leading to an increase in the amount of hydroxyl free radicals formed due to a more violent cavitation bubble collapse. A high ultrasound power would increase the acoustic amplitude, varying the collapse time, temperature and pressure (Chiha et al. 2011; Emery et al. 2005; Gao et al. 2013; Lim et al. 2007). The concentration of $\mathrm{OH}$ radicals was determined based on the methods described by Tai et al. (2004) and Ji et al. (2012). Profile of variation of $\mathrm{OH}$ radicals as a function of time for different power levels is shown in Fig. 3. An increase in the applied ultrasonic power increases the amount of radicals in the solution. Therefore, increase in the number of radicals can be responsible for the enhancement in the pollutant degradation rates with respect to the applied power and the irradiation time.

\section{Effect of pollutant initial concentration}

The effect of pollutant initial concentration on the benzophenone-3 degradation was evaluated. For an initial concentration range of $1.5-4.5 \mathrm{mg} / \mathrm{L}\left(6.6-19.7 \mu \mathrm{mol} \mathrm{L}^{-1}\right)$, different experiments were conducted to determine BP3 initial degradation rate and the extent of removal. Results indicated that the removal of $\mathrm{BP} 3$ decreased from 90.8 to $61.1 \%$ with increasing in the initial concentration. However, as shown in Fig. 4, the initial degradation rate increased with increase in the initial concentration. A linear relationship was not observed, as expected, for a first-order

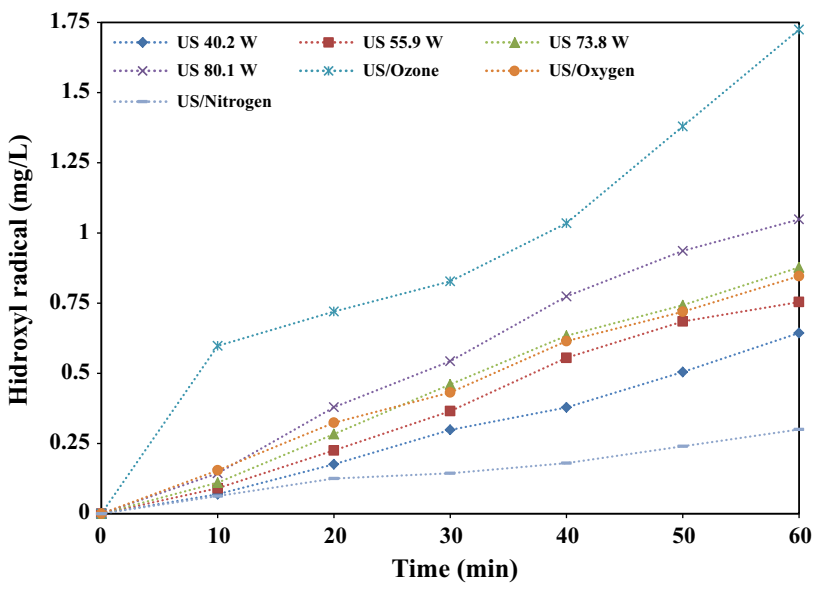

Fig. 3 Effect of different input power levels and gases presence on Hydroxyl free radicals content [frequency: $20 \mathrm{kHz}$, temperature: $25 \pm 2{ }^{\circ} \mathrm{C}$, pollutant initial concentration: $3.9 \mathrm{mg} / \mathrm{L}, \mathrm{pH}$ : natural (6.5), power: $55.9 \mathrm{~W}]$

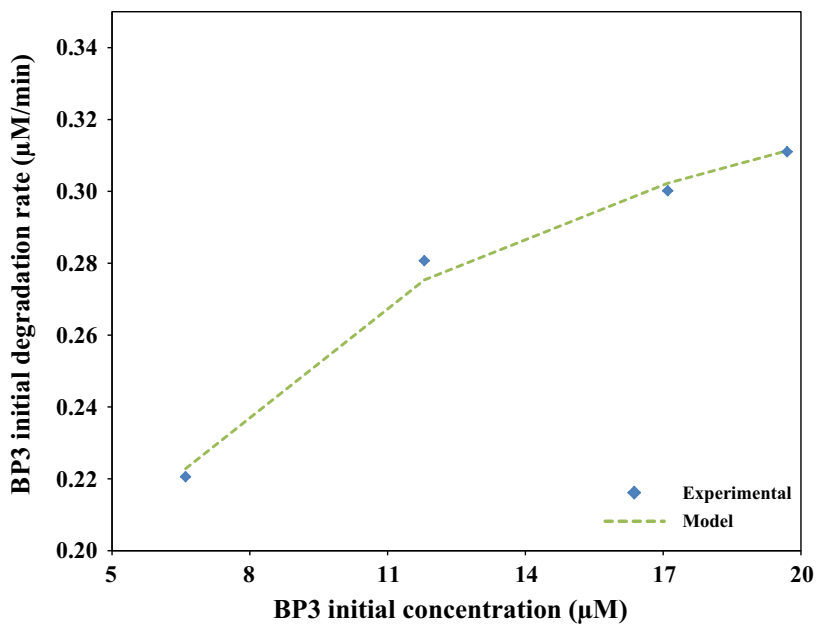

Fig. 4 Initial degradation rate as function of the initial concentration of $\mathrm{BP} 3$ and comparison with model prediction [frequency: $20 \mathrm{kHz}$, temperature: $25 \pm 2{ }^{\circ} \mathrm{C}$, power: $55.9 \mathrm{~W}$, pH: natural (6.5)]

kinetic law. These findings are consistent with the results that a number of research groups have reported for the sonolytic degradation of other organic substances, indicating that the sonochemical degradation does not obey a first-order kinetics (Chiha et al. 2010, 2011; Méndez-Arriaga et al. 2008; Torres-Palma et al. 2008). With the objective of describing the reaction mechanism occurring in the interfacial region of cavitation bubbles in the sonochemical degradation, a heterogeneous kinetics model developed by Okitsu et al. (2005) was used. This model indicates that when pollutant molecules are degraded in the interfacial region of cavitation, the degradation rate can be expressed as Eq. 7, 
$r=\frac{k K C}{1+K C}$

where $r$ is the initial degradation rate $\left(\mu \mathrm{M} \min ^{-1}\right), k$ is the pseudo-rate constant $\left(\mu \mathrm{M} \mathrm{min}{ }^{-1}\right), C$ is the pollutant initial concentration $(\mu \mathrm{M})$ and $K$ is the equilibrium adsorption constant of BP3 toward the effective reaction sites prior to bubble collapse $\left(\mu \mathrm{M}^{-1}\right)$.

Considering the above, the sonolytic degradation data were analyzed by nonlinear curve fitting method using Origin 9.0 software, to fit the kinetic model. A superposition of experimental results and the calculated points are presented in Fig. 4. The values of the model parameters are $0.3893 \mu \mathrm{M} \mathrm{min}{ }^{-1}$ and $0.2041 \mu \mathrm{M}$ for the pseudo-rate constant $(k)$ and the equilibrium adsorption constant $(K)$, respectively. Additionally, the value of the coefficient of determination $\left(R^{2}\right)$ was 0.9872 , indicating an excellent fit of the experimental data with the model. These results imply that the heterogeneous kinetic model describes adequately the BP3 sonochemical degradation, indicating that degradation occurs mainly at the interfacial region of cavitation bubbles by hydroxyl free radicals attack. So, the profile in Fig. 4 shows that at the interfacial region the radical concentration is high and the $\mathrm{OH}$ recombination would be the dominant process (Chiha et al. 2011; Gao et al. 2013). However, when the BP3 initial concentration increases, the fraction of hydroxyl free radical that reacts with the substrate and the degradation rate increases.

\section{Effect of initial pH}

The effect of solution initial $\mathrm{pH}$ on the sonolytic degradation of BP3 was studied. Concentrated solutions of sodium hydroxide and nitric acid were used to adjust $\mathrm{pH}$ of the solution. The pKa value of benzophenone-3 is 8.06 (GagoFerrero et al. 2013). Above this value, ionic BP3 is the predominant specie, and at lower values, BP3 is mainly found in its molecular form. In order to evaluate the effectiveness of ultrasonic treatment on different BP3 forms (ionic and neutral), experiments were carried out at $\mathrm{pH} 2$ and 10 as extreme values and $\mathrm{pH} 6.5$ corresponding to the initial natural $\mathrm{pH}$ of the solution. The effect of solution $\mathrm{pH}$ on the benzophenone3 sonochemical degradation is depicted in Fig. 5. It may be observed from this figure that the decrease in BP3 concentration was faster and higher under acid media. This fact can be attributed to the effect of $\mathrm{pH}$ on the benzophenone-3 ionization. The ionic fraction of $\mathrm{BP} 3$ at the evaluated $\mathrm{pH}$ value can be calculated using Eq. 8 (Chiha et al. 2011),

$\varphi_{\text {ions }}=\frac{1}{1+10^{\left(p K_{a}-p H\right)}}$

BP3 is a nonvolatile compound with a low solubility in water, and as mentioned previously, the region of

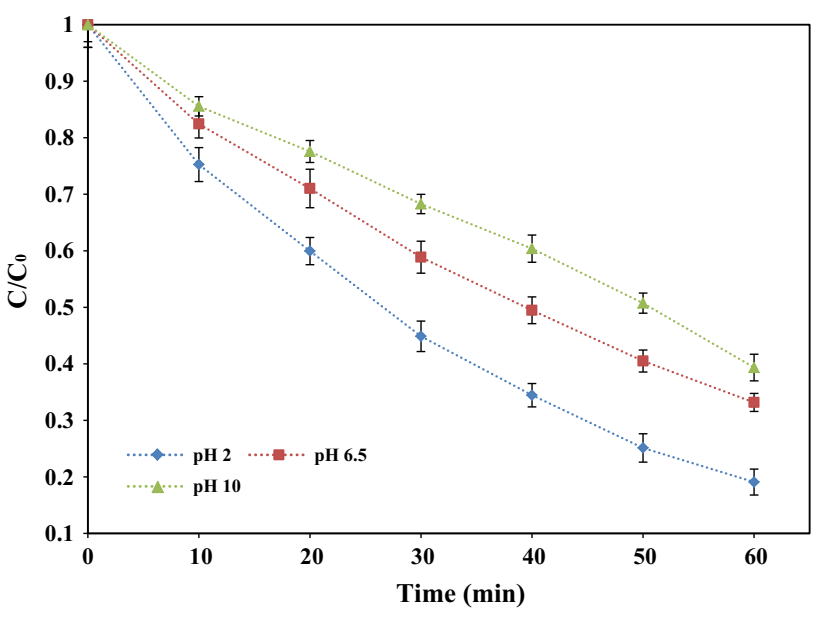

Fig. 5 Effect of the initial $\mathrm{pH}$ on the BP3 degradation (frequency: $20 \mathrm{kHz}$, temperature: $25 \pm 2{ }^{\circ} \mathrm{C}$, pollutant initial concentration: $3.9 \mathrm{mg} / \mathrm{L}$, power: $55.9 \mathrm{~W}$ )

degradation would be at the exterior of the cavitation bubbles, mainly in the interfacial region. The reaction between the free radicals generated by ultrasonic treatment and the pollutant would be enhanced if its hydrophobicity is favoured. According to Eq. 8, BP3 has a high hydrophobic character at $\mathrm{pH} 2$ and 6.5 because it is mainly in its molecular form (ionic fraction $8.71 \times 10^{-5}$ and $2.68 \%$, respectively). Under this condition, the pollutant will be accumulated in the interface of the cavitation bubbles, where the concentration of $\mathrm{OH}$ free radicals is higher, generating a faster degradation of the compound. In contrast, at $\mathrm{pH} 10$ benzophenone- 3 is almost completely in anionic form $\left(\varphi_{\text {ions }} \sim 0.99\right)$ due to the deprotonation of the phenolic group, implying a higher hydrophilicity and solubility. Thus, the degradation would take place at both the interfacial and the bulk solution regions, limiting the pollutant extent of degradation since in the bulk solution the amount of radicals is low due to their low diffusion $(\sim 10 \%$ of the generated in the cavitation bubbles; Méndez-Arriaga et al. 2008).

\section{Effects of different dissolved gases}

The presence of dissolved gases in water can enhance or inhibit the process efficiency of sonochemical treatment of pollutants (Méndez-Arriaga et al. 2008). With the objective of evaluating the effects of the presence of dissolved gases on the BP3 ultrasonic degradation, $\mathrm{O}_{3}, \mathrm{~N}_{2}$ and $\mathrm{O}_{2}$ were introduced into the solution.

\section{Combined ultrasound/ozone degradation}

The combination of ultrasound treatment and ozonation in the removal of organic pollutants has been evaluated by several authors. Results have shown that in combined 
ultrasound/ozone treatments, ultrasound not only promotes ozone mass transfer to the liquid, but also ozone is decomposed thermolytically in the vapor phase of the cavitation bubbles, increasing the rate of formation of hydroxyl free radicals (Eqs. 9-10) (Ji et al. 2012; Weavers et al. 1998). Therefore, it is expected that in a combined treatment, the removal of organic compounds increases in comparison with application of each process separately.

$$
\begin{aligned}
& \mathrm{O}_{3} \rightarrow \mathrm{O}_{2}+\mathrm{O}\left({ }^{3} \mathrm{P}\right) \\
& \mathrm{O}\left({ }^{3} \mathrm{P}\right)+\mathrm{H}_{2} \mathrm{O} \rightarrow \cdot \mathrm{OH}
\end{aligned}
$$

In order to evaluate the effect of the presence of ozone on the ultrasonic treatment of benzophenone-3, experiments were conducted by introducing, $\mathrm{O}_{3}\left(0.5 \mathrm{~mL} \mathrm{~min}^{-1}\right)$ into the reaction media. Figure 6 shows the comparison, in terms of variation in the concentration of $\mathrm{BP} 3$, corresponding to the combined use $\mathrm{US} / \mathrm{O}_{3}$ and each process separately. It is evident that both ozonation and the combined use of ultrasound and $\mathrm{O}_{3}$ increase the pollutant degradation under the studied conditions, attaining in both cases a $100 \%$ removal. However, the degradation is faster in the combined process.

As previously mentioned, incorporating ozone in the system can promote the formation of $\mathrm{OH}^{\cdot}$ free radicals, which together with molecular ozone, would increase the BP3 degradation rate. The amount of radicals generated in the three cases (presented in Fig. 3) confirms that the number of radicals formed follows the order, $\mathrm{US} / \mathrm{O}_{3}>\mathrm{O}_{3}>\mathrm{US}$, and there is a synergy effect between ozone and ultrasound.

\section{Presence of oxygen and nitrogen}

$\mathrm{N}_{2}$ and $\mathrm{O}_{2}$ were introduced at the same flow rates $\left(800 \mathrm{~mL} \mathrm{~min}^{-1}\right)$ into the solution, and results are shown in Fig. 6. It can be noted that the presence of oxygen

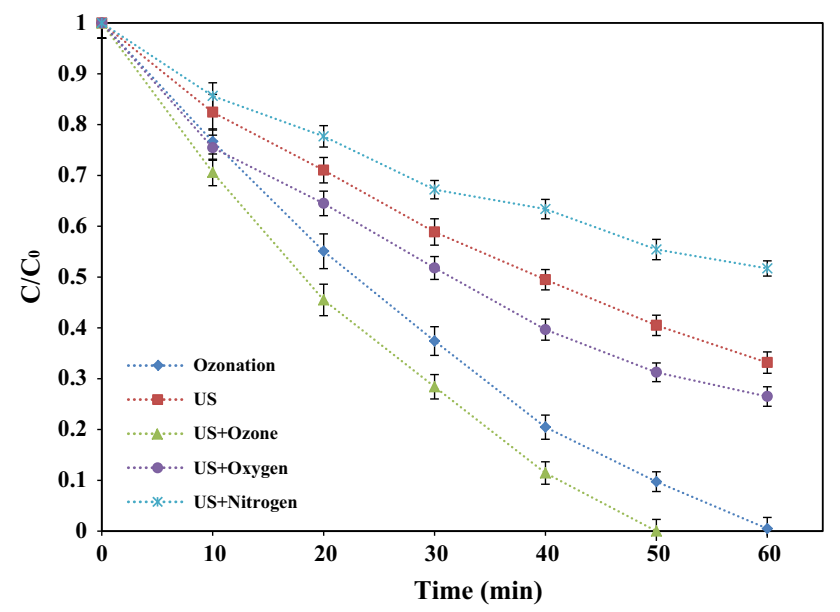

Fig. 6 Effect of different gases on the BP3 degradation rate [frequency: $20 \mathrm{kHz}$, temperature: $25 \pm 2{ }^{\circ} \mathrm{C}$, pollutant initial concentration: $3.9 \mathrm{mg} / \mathrm{L}$, power: $55.9 \mathrm{~W}$, $\mathrm{pH}$ : natural (6.5)] increased the benzophenone-3 degradation, reaching in 60 min a $73.5 \%$ pollutant removal, which is $6.7 \%$ higher than the base treatment (without gas). In contrast, when $\mathrm{N}_{2}$ is present in the solution, BP3 degradation is inhibited, reaching only $48.30 \%$ removal. This can be due to the generation or scavenging of hydroxyl radicals which, as previously discussed, are responsible for degrading the benzophenone-3 in the interfacial region.

Under an $\mathrm{O}_{2}$ atmosphere, additional hydroxyl radicals are generated by molecular oxygen dissociation inside the cavitation bubble (Eqs. 12-13) (Pétrier et al. 2007).

$\mathrm{O}_{2} \rightarrow 2 \mathrm{O}$

$\mathrm{O}+\mathrm{H}_{2} \mathrm{O} \rightarrow 2 \cdot \mathrm{OH}$

Due to the greater availability of these additional $\mathrm{OH}$ radicals, BP3 can be oxidized faster.

On the other hand, the presence of $\mathrm{N}_{2}$ can scavenge the free radicals and inhibit the pollutant degradation (Chiha et al. 2011; Wu et al. 1992) as shown in Eqs. 13-18 (Chiha et al. 2011).

$\mathrm{N}_{2}+\mathrm{OH} \rightarrow \mathrm{NO}_{2}+\mathrm{H}^{\cdot}$

$\mathrm{N}_{2}+\mathrm{O} \rightarrow \mathrm{NO}+\mathrm{N}$

$\mathrm{O}_{2}+\mathrm{N} \rightarrow \mathrm{NO}+\mathrm{O}$

$\mathrm{NO}+\mathrm{O} \rightarrow \mathrm{NO}_{2}$

$\mathrm{NO}+\cdot \mathrm{OH} \rightarrow \mathrm{HNO}_{2}$

$\cdot \mathrm{NO}_{2}+\cdot \mathrm{OH} \rightarrow \mathrm{HNO}_{3}$

The results of the experiments carried out to determine the amount of $\mathrm{OH}^{-}$(Fig. 3) indicated, as expected, that more radicals are formed in the presence of oxygen, while nitrogen reduces the amount of $\mathrm{OH}$.

\section{Effect of chloride, nitrate and bicarbonate ions}

Inorganic ions are present in industrial and natural waters, so their impact on the performance of water treatment processes needs to be investigated. $\mathrm{TiO}_{2}$ photocatalysis, photo-Fenton and $\mathrm{UV} / \mathrm{O}_{3}$ are examples of advanced oxidation process whose performance is affected by the presence of sulfate, chloride, carbonate and bicarbonate ions (Guzman-Duque et al. 2011). In the case of sonochemical treatment, the effect of the presence of inorganic ions has not been clarified. Some reports indicate that sonochemical degradation processes in the presence of inorganic species can be enhanced, while others report that degradation rates are not significantly affected by inorganic ions (Pétrier et al. 2010). The influence of chloride, nitrate and bicarbonate ions in the sonolytic removal of BP3 was investigated. Figure 7 shows the variation of the benzophenone-3 concentration in $60 \mathrm{~min}$ of sonochemical 


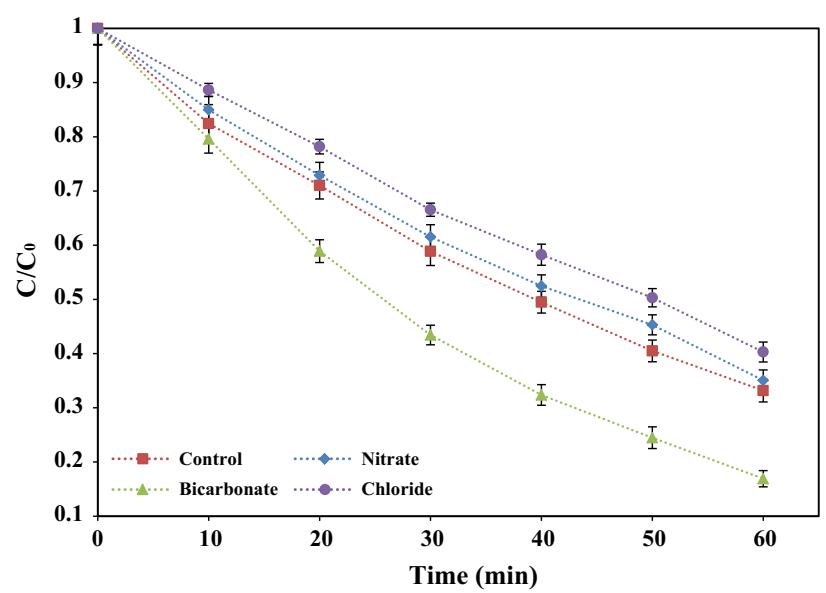

Fig. 7 Effect of the presence of different anions on the BP3 degradation rate [frequency: $20 \mathrm{kHz}$, temperature: $25 \pm 2{ }^{\circ} \mathrm{C}$, pollutant initial concentration: $3.9 \mathrm{mg} / \mathrm{L}$, power: $55.9 \mathrm{~W}, \mathrm{pH}$ : natural (6.5), anion concentration: $5 \mathrm{mmol} / \mathrm{L}$ ]

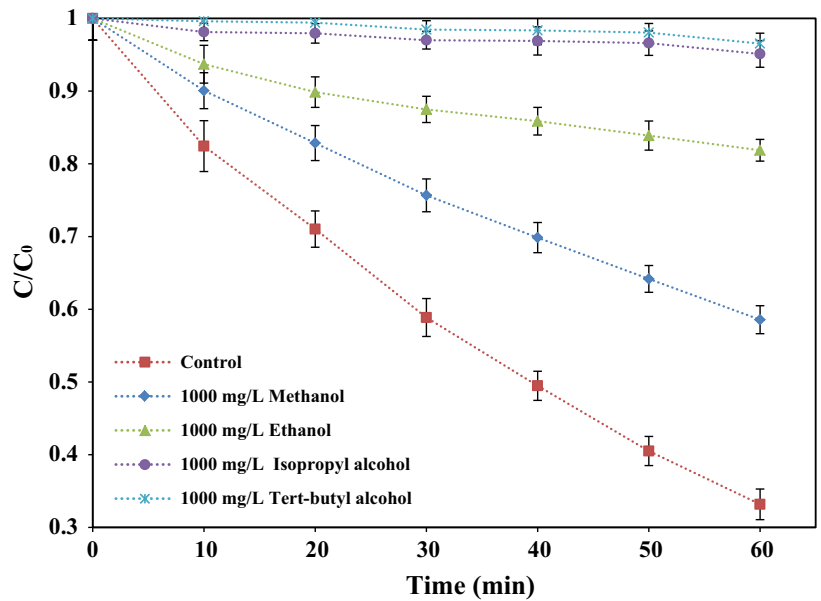

Fig. 8 Effects of different alcohols on the BP3 degradation (frequency: $20 \mathrm{kHz}$, temperature: $25 \pm 2{ }^{\circ} \mathrm{C}$, pollutant initial concentration: $10 \mathrm{mg} /$ L, power: $55.9 \mathrm{~W}, \mathrm{pH}: 6.5$ )

treatment. It can be noted that the presence of $\mathrm{NO}_{3}^{-}$and $\mathrm{Cl}^{-}$inhibited the pollutant removal, while $\mathrm{HCO}_{3}^{-}$anions enhanced the BP3 degradation and the initial degradation rate.

In the presence of anions, two parameters can impact the ultrasonic degradation rate. One is the commonly called "salting out effect," a phenomenon caused by ions in water, which pushes organic pollutants toward the bubble-bulk solution interface leading to accelerated degradation (Gao et al. 2013; Pétrier et al. 2010). Likewise, there are some anions that can react rapidly with reactive oxygen species produced, and compete with the contaminant for the oxidizing agents (Gao et al. 2013). In the case of bicarbonate, it reacts with $\mathrm{OH}^{-}$ radicals to produce the carbonate radical (Eq. 19) (Gao et al. 2013; Guzman-Duque et al. 2011), which, unlike the hydroxyl radicals, can migrate to the bulk solution and promote the pollutant degradation.

$\mathrm{HCO}_{3}^{-}+{ }^{-} \mathrm{OH} \rightarrow \mathrm{CO}_{3}^{-}+\mathrm{H}_{2} \mathrm{O}$

Although $\mathrm{CO}_{3}{ }^{-}$radical is less reactive than hydroxyl radical (Gao et al. 2013), it can attack BP3 molecules in the solution whereas $\mathrm{NO}_{3}^{-}$and $\mathrm{Cl}^{-}$have a scavenging effect that reduce the degradation rate.

\section{Effects of hydroxyl radical scavengers (alcohols)}

Alcohols and other organic species of low molecular weight (four and less carbon atoms) can act as quenchers in reactions with $\mathrm{OH}$ radicals (Behnajady et al. 2008). Therefore, the effect of the presence of four alcohols: methanol, ethanol, 


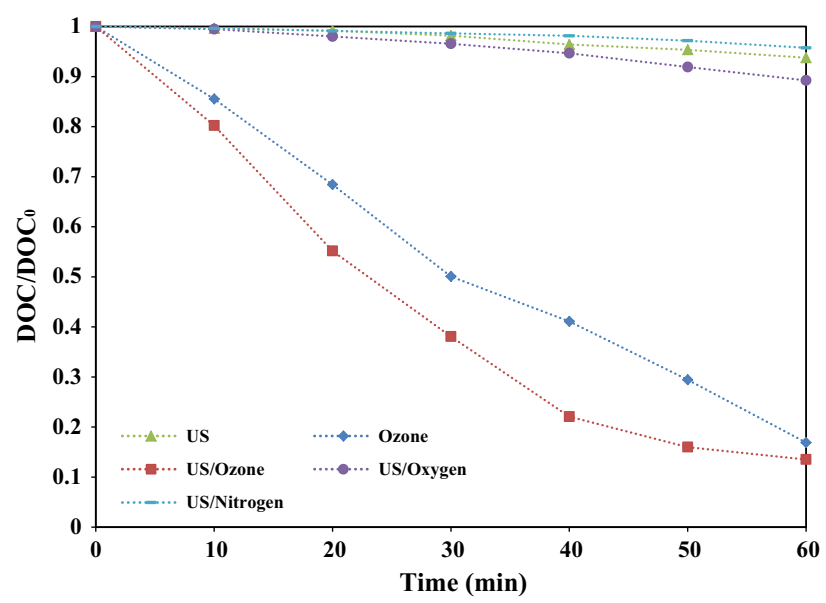

Fig. 9 Variation on $\mathrm{DOC} / \mathrm{DOC}_{0}$ ratio during $\mathrm{BP} 3$ degradation [frequency: $20 \mathrm{kHz}$, temperature: $25 \pm 2{ }^{\circ} \mathrm{C}$, pollutant initial concentration: $3.9 \mathrm{mg} / \mathrm{L}$, power: $55.9 \mathrm{~W}, \mathrm{pH}$ : natural (6.5)]

isopropyl alcohol and tert-butyl alcohol in the sonolytic degradation of BP3 was investigated. Experimental results are depicted in Fig. 8, indicating that all of the four alcohols inhibit the extent of degradation of benzophenone-3. This confirms that hydroxyl free radicals are the main oxidizing agents that are consumed by alcohols. It can be noted that as the alcohol carbon number increases the inhibiting effect also increases. This can be attributed to the possible reaction of hydroxyl free radicals with hydrogens bonded to carbon in alcohol molecules (Behnajady et al. 2008). Likewise, this scavenging activity order was in agreement with the order of alcohols specific heat capacities, which has been reported by other authors, who attributed it to the fact that large specific heat capacities would reduce the maximum size of microbubble and the interfacial temperatures achieved from bubble collapse, resulting in generation of fewer $\mathrm{OH}$ radicals (Gao et al. 2013).

\section{Mineralization of BP3}

The dissolved organic carbon (DOC) analysis of the reaction medium (Fig. 9) indicated that although the extent of benzophenone-3 degradation in all cases studied (without inhibitors and gases) is more than $60 \%$, the decrease in DOC is $<10 \%$. This suggests that BP3 is mostly transformed into organic by products with lower volatility and higher hydrophilicity, which migrate to the bulk solution, where the concentration of radicals is much lower than the interface. Recently, Gago-Ferrero et al. (2013) reported a study on the ozonation and peroxone oxidation of BP3, in which the identified degradation products were hydroxylated derivatives formed by a non-specific attack of hydroxyl radicals at different moieties of the solute molecule. A similar range of products can be generated through ultrasonic treatment. In the presence of gases, it can be noted that $\mathrm{O}_{3}$ enhances the removal of organic compounds present in the solution. This fact can be due to the presence of molecular ozone which would oxidize byproducts that because of their solubility and volatility could not be attacked by the hydroxyl radicals generated by ultrasound or pyrolized inside the cavitation bubbles. Under $\mathrm{O}_{2}$ and $\mathrm{N}_{2}$ atmospheres, there is no significant change in DOC concentration.

\section{Conclusion}

This study shows how hydroxyl free radicals formed from the cavitation bubbles collapse were responsible for removing benzophenone-3 (BP3), one of the most used UV filters and endocrine disrupting compounds. The results indicate that the ultrasonic applied power, solution $\mathrm{pH}$, the presence of some gases, ions and alcohols can play an important role in terms of enhancement/inhibition of pollutant removal.

Increasing the applied power between 40.2 and $80.1 \mathrm{~W}$ increased the initial degradation rate of BP3, getting with the higher power an extent of the degradation equivalent to $91.37 \%$. Likewise, the excellent fit between the experimental data and the model developed by Okitsu et al. indicated that the pollutant is degraded mainly in the interface bubble-bulk solution region.

The acidic medium enhanced the degradation due to the increased hydrophobicity of the compound. In this regard, at a natural $\mathrm{pH}(6.5)$ a $66.83 \%$ removal was achieved, but at a pH 2 removal was $80.91 \%$. The presence of bicarbonate anions, oxygen and ozone increased the BP3 
removal, since they can contribute to the generation of more hydroxyl free radicals, in the specific case of $\mathrm{O}_{3}$, molecular ozone also could oxidize the substrate, while nitrate and chloride anions, nitrogen and alcohols are inhibiting species.

On the other hand, ultrasound alone does not seem to cause a significant reduction in dissolved organic carbon; however, in combination with ozonation, more than $80 \%$ DOC reduction can be achieved.

In general, the research findings indicate that ultrasound is a potentially effective method for BP3 removal in water, offering a new option for wastewater treatment.

Acknowledgments The authors want to thank the Canadian Bureau for International Education (CBIE) and its Emerging Leaders in the Americas Program, the Colombian Administrative Department of Science, Technology and Innovation (COLCIENCIAS), the University of Saskatchewan and the "Fondo de Sostenibilidad 2014-2015" of the University of Antioquia Research Vice-rectory for the support of this work and travel of Mr. ZB to Canada.

\section{References}

Balmer M, Buser H, Müller M, Poiger T (2005) Occurrence of some organic UV filters in wastewater, in surface waters, and in fish from swiss lakes. Environ Sci Technol 39(4):953-962

Behnajady MA, Mordishahla N, Shokri N, Vadhi B (2008) Effect of operational parameters on degradation of Malachite Green by ultrasonic irradiation. Ultrason Sonochem 15(6):1009-1014

Blüthgen N, Zucchi S, Fent K (2012) Effects of the UV filter benzophenone-3 (oxybenzone) at low concentrations in zebrafish (Danio rerio). Toxicol Appl Pharmacol 263(2):184-194

Chiha M, Merouani S, Hamadaoui O, Baup S, Gondrexon N, Pétrier C (2010) Modeling of ultrasonic degradation of non-volatile organic compounds by Langmuir-type kinetics. Ultrason Sonochem 17(5):773-782

Chiha M, Hamadaoui O, Baup S, Gondrexon N (2011) Sonolytic degradation of endocrine disrupting chemical 4-cumylphenol in water. Ultrason Sonochem 18(5):943-950

Dailianis S, Tsarpali V, Melas K, Karapanagioti HK, Manariotis ID (2014) Aqueous phenanthrene toxicity after high-frequency ultrasound degradation. Aquat Toxicol 147:32-40

Emery R, Papadaki M, Freitas dos Santos LM, Mantzavinos D (2005) Extent of sonochemical degradation and charge of toxicity of a pharmaceutical precursor (triphenylphosphine oxide) in water as a function of treatment conditions. Environ Int 31(2):207-211

Fent K, Zenker A, Rapp M (2010a) Widespread occurrence of estrogenic UV-filters in aquatic ecosystems in Switzerland. Environ Pollut 158(5):1817-1824

Fent K, Kunz P, Zenker A, Rapp M (2010b) A tentative environmental risk assessment of the UV-filters 3-(4-methylbenzylidene-camphor), 2-ethyl-hexyl-4-trimethoxycinnamate, benzophenone-3, benzophenone-4 and 3-benzylidene camphor. Mar Environ Res 69:S4-S6

Gago-Ferrero P, Badia-Fabregat M, Olivares A, Piña B, Blánquez P, Vicent T, Caminal G, Díaz-Cruz MS, Barceló D (2012) Evaluation of fungal- and photo-degradation as potential treatments for the removal of sunscreens BP3 and BP1. Sci Total Environ 427-428:355-363
Gago-Ferrero P, Demeestere K, Díaz-Cruz MS, Barceló D (2013) Ozonation and peroxone oxidation of benzophenone-3 in water: effect of operational parameters and identification of intermediate products. Sci Total Environ 443:209-217

Gao Y, Gao N, Deng Y, Gu J, Gu Y, Zhang D (2013) Factor affecting sonolytic degradation of sulfamethazine in water. Ultrason Sonochem 20(6):1401-1407

Garcia H, Hoffman C, Kinney K, Lawler D (2011) Laccase-catalyzed oxidation of oxybenzone in municipal wastewater primary effluent. Water Res 45(5):1921-1932

Guzman-Duque F, Pétrier C, Pulgarín C, Peñuela G, Torres-Palma R (2011) Effects of sonochemical parameters and inorganic ions during the sonochemical degradation of crystal violet in water. Ultrason Sonochem 18(1):440-446

Henglein A (1987) Sonochemistry: historical developments and modern aspects. Ultrasonics 25(1):7-16

Hoffmann MR, Hua I, Höchemer R (1996) Application of ultrasonic irradiation for the degradation of chemical contaminants in water. Ultrason Sonochem 3(3):S163-S172

Ji G, Zhang B, Wu Y (2012) Combined ultrasound/ozone degradation of carbazole in APG1214 surfactant solution. J Hazard Mater 225-226:1-7

Li W, Ma Y, Guo Ch, Hu W, Liu K, Wang Y, Zhu T (2007) Occurrence and behavior of four of the most used sunscreen UV filters in a wastewater reclamation plant. Water Res 41(15):3506-3512

Lim MH, Kim SH, Kim YU, Khim J (2007) Sonolysis of chlorinated compounds in aqueous solution. Ultrason Sonochem 14(2):93-98

Mahvi AH (2009) Application of ultrasonic technology for water and wastewater treatment. Iran J Public Health 38(2):1-17

Mason TJ, Lorimer JP, Bates DM (1992) Quantifying sonochemistry: casting some light on a 'black art'. Ultrasonics 30(1):40-42

Méndez-Arriaga F, Torres-Palma R, Pétrier C, Esplugas S, Gimenez J, Pulgarín C (2008) Ultrasonic treatment of water contaminated with ibuprofen. Water Res 42(16):4243-4248

Okitsu K, Iwasaki Y, Yobiko Y, Bandow H, Nishimura Y, Maeda Y (2005) Sonochemical degradation of azo dyes in aqueous solution: a new heterogeneous kinetics model taking into account the local concentration of $\mathrm{OH}$ radicals and azo dyes. Ultrason Sonochem 12(4):255-262

Pétrier C, Combet E, Mason T (2007) Oxygen-induced concurrent ultrasonic degradation of volatile and non-volatile aromatic compounds. Ultrason Sonochem 14(2):117-121

Pétrier C, Torres-Palma R, Combet E, Sarantakos G, Baup S, Pulgarín C (2010) Enhanced sonochemical degradation of bisphenol-A by bicarbonate ions. Ultrason Sonochem 17(1):111-115

Siddique M, Farooq R, Price GJ (2014) Synergistic effects of combining ultrasound with the Fenton process in the degradation of Reactive Blue 19. Ultrason Sonochem 21(3):1206-1212

Tai Ch, Peng J, Liu J, Jiang G, Zou H (2004) Determination of hydroxyl radicals in advanced oxidation processes with dimethyl sulfoxide trapping and liquid chromatography. Anal Chim Acta 527(1):73-80

Torres-Palma R, Pétrier C, Combet E, Carrier M, Pulgarín C (2008) Ultrasonic cavitation applied to the treatment of bisphenol A. Effect of sonochemical parameters and analysis of BPA byproducts. Ultrason Sonochem 14(4):605-611

Vione D, Caringella R, De Laurentiis E, Pazzi M, Mineiro C (2013) Phototransformation of the sunlight filter benzophenone-3 (2- 
hydroxy-4-methoxybenzophenone) under conditions relevant to surface waters. Sci Total Environ 463-464:243-251

Weavers LK, Ling FH, Hoffmann MR (1998) Aromatic compound degradation in water using a combination of sonolysis and ozonolysis. Environ Sci Technol 32(18):2727-2733
Wu JM, Huang HS, Livengood CD (1992) Ultrasonic destruction of chlorinated compounds in aqueous solution. Environ Prog 11(3):195-201

Yang B, Ying G (2013) Oxidation of benzophenone-3 during water treatment with ferrate (VI). Water Res 47(7):2458-2466 